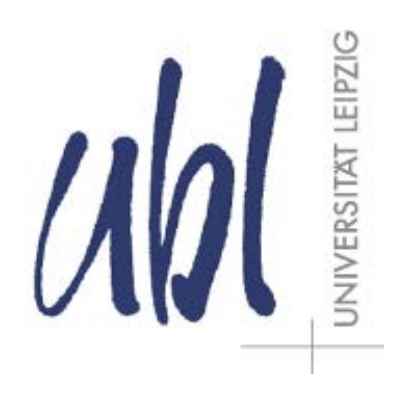

Institute of Medical Physics and Biophysics

Medical Department, Leipzig University

Author Manuscript

(C) 2016. This manuscript version is made available under the CC-BY-NC-ND 4.0 license

http://creativecommons.org/licenses/by-nc-nd/4.0/

Published in final edited form as:

Prostaglandins, Leukotrienes and Essential Fatty Acids

(PLEFA), 2016 Apr; 107:12-21.

Available at: http://dx.doi.org/10.1016/j.plefa.2016.02.001.

\title{
IMPACT OF SIMULTANEOUS STIMULATION OF 5- LIPOXYGENASE AND MYELOPEROXIDASE IN HUMAN NEUTROPHILS
}

\author{
Josefin Zschaler, Jürgen Arnhold \\ Institute for Medical Physics and Biophysics, Medical Faculty, Leipzig University, \\ Leipzig, Germany
}

\begin{abstract}
Human neutrophil 5-lipoxygenase (5-LOX) oxidizes arachidonic acid (AA) to 5Shydro(pero)xy-6E,8Z,11Z,14Z-eicosatetraenoic acid (5-H(p)ETE) and leukotriene (LT)A4, which is further converted to the chemoattractant LTB4. These cells contain also the heme enzyme myeloperoxidase (MPO) producing several potent oxidants such as hypochlorous acid ( $\mathrm{HOCl})$. Previously, it was shown that MPO-metabolites influence 5-LOX product formation. Here, we addressed the question, whether a simultaneous activation of MPO and 5-LOX in neutrophils results in comparable changes of 5-LOX activity.

Human neutrophils were stimulated with $\mathrm{H} 2 \mathrm{O} 2$ or phorbol 12-myristate 13-acetate (PMA) for MPO activation and subsequently treated with calcium ionophore A23187 inducing 5-LOX product formation on endogenous AA. Special attention was drawn to neutrophil vitality, formation of MPO-derived metabolites and redox status. The pre-stimulation with $\mathrm{H} 2 \mathrm{O} 2$ resulted in a concentration-dependent increase in the ratio of 5-HETE to the sum of LTB4 + 6-trans-LTB4 in consequence of MPO activation. Thereby no impairment of cell vitality and only a slightly reduction of total glutathione level was observed. An influence of MPO on 5-LOX product formation could be suggested using an MPO inhibitor. In contrast, the pre-stimulation with PMA resulted in different changes of 5-LOX product formation leading to a reduced amount of 5-HETE unaffected by MPO inhibition. Furthermore, impaired cell vitality and diminished redox status was detected after PMA stimulation. Nevertheless, a MPO-induced diminution of LTB4 was obvious. Further work is necessary to define the type of 5-LOX modification and investigate the effect of physiological MPO activators.
\end{abstract}




\section{Abbreviations}

MVP, 1-methyl-2-vinylpyridinium triflate; 4-ABAH, 4-aminobenzoic acid hydrazide; APF, aminophenyl fluorescein; JC-1, J-aggregate forming cationic dye

\section{Keywords}

Leukotriene, $\mathrm{HOCl}$, Inflammation, Glutathione, Hydrogen peroxide

\section{Introduction}

The inflammatory response against infectious agents is characterized by a rapid recruitment of neutrophils from peripheral blood to the inflammatory loci driven by chemotactic agents like IL-8, fMet-Leu-Phe and others [Witko-Sarsat et al. 2000]. During this movement, neutrophils produce in a 5-lipoxygenase (5-LOX)-dependent reaction the potent autocrine chemotactic molecule leukotriene $\mathrm{B}_{4}\left(\mathrm{LTB}_{4}\right)$. Thereby, 5-LOX, a non-heme-iron dioxygenase, translocates to the nuclear envelope, interacts with 5-LOX activating protein (FLAP) and oxygenates arachidonic acid (AA), which is liberated by the action of cytosolic phospholipase $A_{2}\left(C P L A_{2}\right)$ [Radmark et al. 2015]. The lipoxygenase reaction is initiated by abstraction of a hydrogen atom from C7 of AA by ferric 5-LOX [Rouzer and Samuelsson 1986] generating a radical, which migrates to the $C 5$ position, where it reacts with dioxygen forming a peroxyl radical. Subsequently, the peroxyl anion is formed by interaction with ferrous 5-LOX yielding 5S-hydroperoxy-6E,8Z,11Z,14Z-eicosatetraenoic acid (5-HpETE) after protonation [Haeggstrom and Funk 2011]. Human 5-LOX also possesses a secondary leukotriene $\mathrm{A}_{4}\left(\mathrm{LTA}_{4}\right)$ synthase activity [Rouzer et al. 1986]. For this purpose a hydrogen atom at the $\mathrm{C} 10$ position of 5 -HpETE is abstracted, followed by radical migration, rearrangement of double bonds and formation of an epoxide moiety [Maas et al. 1982]. Thereafter, unstable LTA $_{4}$ is hydrolyzed to leukotriene $B_{4}\left(L_{T B}\right)$ by the action of LTA $_{4}$ hydrolase [Newcomer and Gilbert 2010].

During respiratory burst in phagocytosing neutrophils a high proportion of consumed dioxygen (reported values of $28-72 \%$ ) is converted into hypochlorous acid $(\mathrm{HOCl})$ by the heme protein myeloperoxidase (MPO), which is present in azurophilic granules [Klebanoff et al. 2013]. Upon reaction with $\mathrm{H}_{2} \mathrm{O}_{2}$, oxidized MPO can abstract two electrons from chloride generating $\mathrm{HOCl}$ [Arnhold and Flemmig 2010]. However, the sole impact of $\mathrm{HOCl}$ on microbe killing is a matter of considerable debate [Nauseef 2007; Segal 2005]. When $\left[{ }^{13} \mathrm{C}_{6}\right]$-tyrosine labelled Staphylococcus aureus are phagocytosed from neutrophils, chlorinated bacterial proteins could be detected only after 5 min leading to microbe killing. But, the majority of chlorinated tyrosine residues, this means $94 \%$, were detected in neutrophil proteins [Chapman et al. 2002]. Furthermore, individuals with MPO deficiency, occurring with a relative high prevalence, showed only partially pathogen-dependent problems with severe infections indicating MPO-independent host defense mechanism that compensate in part their lack of MPO [Klebanoff 1970; Kutter 1998; Parry et al. 1981]. Therefore, the implication of $\mathrm{HOCl}$ in further biological aspects could be suggested. Typical reaction partners of $\mathrm{HOCl}$ are thiols, thioether and amino groups. This enables $\mathrm{HOCl}$ to oxidize amino acid residues such as cysteine, methionine, tyrosine, tryptophan, and lysine [Pattison and Davies 2001]. Interestingly, with respect to the above mentioned $\mathrm{HOCl}$ preference for neutrophil proteins, it could be shown that different granule proteins can be irreversible inactivated by $\mathrm{HOCl}$ or the $\mathrm{MPO}-\mathrm{H}_{2} \mathrm{O}_{2}-\mathrm{Cl}^{-}$system [Fu et al. 2003; Hirche et al. 2005; Shao et al. 2005]. Additionally, $\mathrm{HOCl}$ can react with amines to produce chloramines or 
$\mathrm{N}$-chlorinated derivatives with longer lifetime and membrane permeability [Grisham et al. 1984]. Furthermore, $\mathrm{HOCl}$ can readily pass through membranes assuming MPO-dependent oxidative modification of cytosolic proteins [Vissers and Winterbourn 1995; WilkieGrantham et al. 2015].

Both neutrophil enzymes, 5-LOX and MPO, are sequentially activated during migration and in response to pathogen recognition, respectively. Here, the question arises whether $\mathrm{HOCl}$, a potent amino acid-oxidizing agent, could affect the activity or product profile of 5-LOX. Previously, we demonstrated that MPO-derived oxidants exhibited a considerable impact on human recombinant 5-LOX, impairing the epoxidation of 5-HpETE, whereas the hydroperoxidation of arachidonic acid was unaffected [Zschaler et al. 2015]. Thereby, HOCl and $\mathrm{HOBr}$, a further prominent hypohalous acid produced from peroxidases, increased the ratio of $5-\mathrm{H}(\mathrm{p}) \mathrm{ETE}$ to 6-trans- $\mathrm{LTB}_{4}$ in a concentration-dependent manner. Comparable results were obtained with the MPO- $\mathrm{H}_{2} \mathrm{O}_{2}-\mathrm{Cl}^{-}$system, when glucose oxidase and glucose were applied as a source of $\mathrm{H}_{2} \mathrm{O}_{2}$. This was necessary due to a strong impairment of 5-LOX activity by $\mathrm{H}_{2} \mathrm{O}_{2}$. These results implicate, that MPO could terminate the 5-LOX dependent formation of $\mathrm{LTB}_{4}$, raising the question of whether that could be of importance in human neutrophils.

The aim of this study was to assess the simultaneous activation of MPO and 5-LOX in human neutrophils by taking the activity and product profile of 5-LOX under consideration. Therefore, different MPO-stimulants were investigated. Analysis was performed by reversephase high-performance liquid chromatography (RP-HPLC) and flow cytometry. Further attention was paid on cell vitality, MPO activation and redox status of stimulated neutrophils. We could demonstrate MPO-induced changes of 5-LOX product formation in neutrophils after pre-stimulation with $\mathrm{H}_{2} \mathrm{O}_{2}$ or phorbol 12-myristate 13-acetate (PMA) followed by addition of the calcium ionophore A23187. 


\section{Material and methods}

\section{Material}

The chemicals were obtained from the following sources: aminophenyl fluorescein (APF) and HPLC-standards 5S-hydroperoxy-6E,8Z,11Z,14Z-eicosatetraenoic acid (5-HpETE), 5Shydroxy-6E,8Z,11Z,14Z-eicosatetraenoic acid (5-HETE), 5S,12R-dihydroxy-6E,8E,10E,14Zeicosatetraenoic acid (5,12-DiHETE), 5-oxo-6E,8Z,11Z,14Z-eicosatetraenoic acid (5-oxo-ETE), $\mathrm{LTB}_{4}$, prostaglandin $\mathrm{B}_{2}\left(\mathrm{PGB}_{2}\right)$ and AA were from Cayman Chemical (distributed by Biomol, Hamburg, Germany); HPLC solvents were from Carl Roth (Karlsruhe, Germany); glutathione colorimetric detection kit from Arbor Assays (Ann Arbor, Michigan, United States); biocoll (10 mM HEPES, $1.077 \mathrm{~g} /$, isotone) from Biochrom (Berlin, Germany) and all other chemicals including the JC-1 staining kit (CS0390) were from Sigma (Taufkirchen, Germany).

Working solutions of $\mathrm{H}_{2} \mathrm{O}_{2}$ were prepared by dilution of the corresponding stock solutions. Their concentrations were determined spectrophotometrically using $\varepsilon_{240}=43.6 \mathrm{M}^{-1} \mathrm{~cm}^{-1}$ [Beers and Sizer 1952]. The buffer system hanks' balanced salt solution (HBSS) with and without $\mathrm{Ca}^{2+}$ for the resuspension of neutrophils was prepared daily and adjusted to $\mathrm{pH}$ 7.4.

\section{Isolation of neutrophil granulocytes}

Neutrophils were isolated from heparinized peripheral human blood $(10 \mathrm{U} / \mathrm{ml})$, obtained from healthy volunteers after written consent, by dextran-enhanced sedimentation in the presence of $2 \%$ dextran for an hour, followed by a density centrifugation (biocoll $1.077 \mathrm{~g} / \mathrm{l}$, $20^{\circ} \mathrm{C}, 400 \mathrm{~g}, 20 \mathrm{~min}$ ). Remaining erythrocytes in the cell pellet were lysed by addition of one part distilled $\mathrm{H}_{2} \mathrm{O}$ and incubation for $30 \mathrm{~s}$. Then, five parts of $\mathrm{HBSS}$ without $\mathrm{Ca}^{2+}$ were added and after centrifugation this procedure was repeated. Neutrophils with a purity as well as vitality higher than $90 \%$ were isolated.

\section{Determination of 5-LOX products from neutrophils by RP-HPLC}

Neutrophils $\left(5 \times 10^{6}\right.$ cells $/ \mathrm{ml}$ in HBSS with $\left.\mathrm{Ca}^{2+}\right)$ were incubated in the presence or absence of the MPO inhibitor 4-aminobenzoic acid hydrazide (4-ABAH) with a final concentration of $2.5 \mathrm{mM}$ for $15 \mathrm{~min}$ followed by stimulation with PMA or $\mathrm{H}_{2} \mathrm{O}_{2}$ for 20 min. During the last 5 min $\mathrm{Ca}^{2+}$ ionophore $\mathrm{A} 23187$ was added. All incubation steps took place at $37^{\circ} \mathrm{C}$ in a final volume of $1 \mathrm{ml}$. Control experiments without the addition of inhibitor or stimulant were incubated for comparable duration. Afterwards, cell stimulation was stopped by addition of $1.01 \mathrm{ml}$ ice-cold methanol containing $200 \mathrm{ng} \mathrm{PGB}_{2}$ as internal standard. Samples were acidified with $30 \mu \mathrm{l}$ of $1 \mathrm{~N} \mathrm{HCl}$, mixed for $30 \mathrm{~s}$ and incubated at $4{ }^{\circ} \mathrm{C}$ for $30 \mathrm{~min}$. The precipitate was separated by centrifugation $\left(4^{\circ} \mathrm{C}, 10,000 \mathrm{~g}, 10 \mathrm{~min}\right)$ and supernatants were applied to $\mathrm{C}_{18}$ solid-phase extraction columns (100 mg, Discovery DSC-18 SPE Tube, Sigma, Taufkirchen, Germany) preconditioned with $1 \mathrm{ml}$ methanol and $1 \mathrm{ml} \mathrm{H}_{2} \mathrm{O}$. The columns were washed with $1 \mathrm{ml} \mathrm{H} \mathrm{H}_{2} \mathrm{O}$ and $1 \mathrm{ml} \mathrm{H} \mathrm{H}_{2} \mathrm{O} /$ methanol (75/25, v/v). 5-LOX metabolites were eluted with $300 \mu \mathrm{l}$ methanol. Extraction was performed by centrifugation $\left(10 \mathrm{~g}, 4^{\circ} \mathrm{C}\right)$. The samples were analyzed by RP-HPLC after maximal storage at $-80^{\circ} \mathrm{C}$ for $24 \mathrm{~h}$. Here, a $\mathrm{C}_{18}$ column (Supelcosil LC-18-DB, $25 \mathrm{~cm} \times 4.6 \mathrm{~mm}$ i.d., $5 \mu \mathrm{m}$ ) was used with an isocratic eluent consisting of acetonitrile/ $\mathrm{H}_{2} \mathrm{O} /$ acetic acid $(60 / 40 / 0.2, \mathrm{v} / \mathrm{v} / \mathrm{v})$ and a flow rate of $1 \mathrm{ml} / \mathrm{min}$. The eluate was monitored at $234 \mathrm{~nm}$ (quantification of conjugated dienes) and $270 \mathrm{~nm}$ (quantification of conjugated trienes). The HPLC device consisted of a Shimadzu liquid chromatographic system equipped with a Shimadzu LC-10ATvp isocratic solvent delivery system, Shimadzu SPD-10Avp dual wavelength absorbance detector, Shimadzu CTO-10ASvp column oven $\left(35^{\circ} \mathrm{C}\right)$ and Rheodyne injector with $20 \mu \mathrm{l}$ loop volume. Major lipoxygenase 
products $\left(5-\mathrm{H}(\mathrm{p}) \mathrm{ETE}, \mathrm{LTB}_{4}\right.$ and 6-trans-LTB 4 ) were quantified using a calibration curve (13-point calibration) of the appropriate synthetic standards. Both forms of the nonenzymatic hydrolysis product 6 -trans-LTB 4 (5S,12S/R-DiHETE) eluted at the same retention time and were measured as one product. $\mathrm{LTB}_{4}$ was quantified using the 6-trans-LTB calibration curve. Within each experiment, samples were referenced to the internal standard $\mathrm{PGB}_{2}$

\section{Determination of cell vitality using JC-1}

Cell vitality of neutrophils were assessed using the lipophilic, cationic dye JC-1 (J-aggregate forming cationic dye: 5, ', $, 6,6^{\prime}$-tetrachloro-1,1',3,3'-tetraethylbenzimidazolocarbocyanine iodide). In vital cells JC-1 accumulates in mitochondrial matrix forming red fluorescent JC-1 aggregates. Upon changes of the mitochondrial electrochemical potential for example through the initiation of apoptosis, the JC-1 dye dispersed throughout the entire cell preventing JC-1 aggregate formation and leading to a shift to green fluorescence of JC-1 monomers. The cell vitality is defined as percentage of live, vital cells in the whole neutrophil population with intact membrane potential as assessed by red fluorescent JC-1 aggregates. For JC- 1 staining $1 \times 10^{6}$ cells were resuspended in $500 \mu \mathrm{HBSS}$ without $\mathrm{Ca}^{2+}$ and mixed with $500 \mu \mathrm{J} \mathrm{JC}-1$ staining buffer yielding a final concentration of $0.77 \mu \mathrm{M} \mathrm{JC}-1$. As positive control valinomycin was added in a concentration of $4.3 \mu \mathrm{M}$ that dissipates the mitochondrial electrochemical potential. Samples were stained with $\mathrm{JC}-1$ at $37^{\circ} \mathrm{C}$ for $10 \mathrm{~min}$, washed with HBSS without $\mathrm{Ca}^{2+}(400 \mathrm{~g}, 5 \mathrm{~min})$ and analyzed by flow cytometry.

\section{Analysis of MPO activity by flow cytometry of APF-stained cells}

Neutrophils $\left(5 \times 10^{6}\right.$ cells $/ \mathrm{ml}$ in HBSS with $\left.\mathrm{Ca}^{2+}\right)$ were incubated in the presence or absence of the MPO inhibitor 4-ABAH with a final concentration of $2.5 \mathrm{mM}$ for $15 \mathrm{~min}$. Afterwards, cells were stained with $10 \mu \mathrm{M}$ APF for 15 min followed by 20 min stimulation with PMA or $\mathrm{H}_{2} \mathrm{O}_{2}$. During the last 5 min $\mathrm{Ca}^{2+}$ ionophore $\mathrm{A} 23187$ was added. All incubation steps took place at $37^{\circ} \mathrm{C}$. Thereafter, cells were washed by centrifugation ( $400 \mathrm{~g}, 5 \mathrm{~min}$ ) and analyzed using flow cytometry.

\section{Flow cytometry}

Fluorescence intensity of cells was measured by FACSCalibur (Becton, Dickinson and Company, Franklin Lakes, New Jersey, United States) supplied with a $488 \mathrm{~nm}$ argon laser. Fluorescence of JC-1 monomers and aggregates was detected in FL1 channel (bandpass: $530 \mathrm{~nm} \pm 15 \mathrm{~nm}$ ) and FL2 channel (bandpass: $585 \mathrm{~nm} \pm 21 \mathrm{~nm}$ ), respectively. Both JC-1 monomer and aggregate fluorescence intensities were compensated. Fluorescence of APF stained cells was detected in FL1 channel (bandpass: $530 \mathrm{~nm} \pm 15 \mathrm{~nm}$ ). For each sample, $10^{4}$ events were measured and results were analyzed using the software 'Flowing Software 2.5.1' by Perttu Terho (Cell Imaging Core, Turku Centre for Biotechnology, Finland).

\section{Quantification of total glutathione}

Neutrophils $(5 \times 106$ cells $/ \mathrm{ml}$ in HBSS with $\mathrm{Ca} 2+)$ were incubated as described earlier (Determination of 5-LOX products from neutrophils by RP-HPLC) for simultaneous activation of 5-LOX and MPO. Then, cells were washed with HBSS without Ca2+ for two times ( $400 \mathrm{~g}, 5 \mathrm{~min}$ ) and resuspended in $50 \mu \mathrm{l} \mathrm{HBSS}$ without Ca2+. The measurement of glutathione $(\mathrm{GSH})$ based on the quantification of free thiol groups after protein precipitation. Thereby, total glutathione was measured using a glutathione reductase/NADPH-system. Oxidized glutathione (GSSG) was quantified after blockage of free glutathione using 1-methyl-2-vinylpyridinium triflate (MVP) added directly after sample

Prostaglandins, Leukotrienes and Essential Fatty Acids (PLEFA), provided by University Library Leipzig [2017] 
generation. Therefore, each sample was divided to two parts. MVP was applied to one part in a final concentration of $1 \mathrm{mM}$. Equal amount of $\mathrm{H} 2 \mathrm{O}$ was added to the other part. Afterwards, samples were immediately stored at $-80^{\circ} \mathrm{C}$. For glutathione quantification samples were mixed with $200 \mu \mathrm{l} 5 \% 5$-sulfo-salicylic acid dehydrate solution and precipitate and supernatant were separated by centrifugation $\left(4^{\circ} \mathrm{C}, 13,000 \mathrm{~g}, 10 \mathrm{~min}\right)$. Supernatant was diluted four-fold with assay buffer and transferred to a 96-well plate. Hereinafter, colorimetric detection assay mixture and the glutathione reductase/NADPH-system, obtained from Arbor Assays (K0006-H1, Ann Arbor, Michigan, United States), were added to the sample and absorbance at $405 \mathrm{~nm}$ was measured for $15 \mathrm{~min}$ using the microplate reader Tecan Infinite 200 PRO (Männedorf, Switzerland). Oxidized glutathione (GSSG) was detected in samples with MVP blocking any free GSH in the sample. The samples that have not been treated with MVP were used to measure total glutathione. The amount of free GSH in the sample was calculated from the difference between total glutathione and GSH generated from GSSG. The standard curve was prepared with GSSG also in two parts, whereby to one part MVP was transferred comparable to the sample mixture.

\section{Statistical analysis}

The data are reported as means \pm standard deviation of at least three independent experiments. Statistical evaluation of the data was performed by Student's two-tailed t test for independent means to compare treated samples and the appropriate control. 


\section{Results}

\section{Stimulation of neutrophils for 5-LOX activation}

Human neutrophils were stimulated with increasing concentrations of the calcium ionophore A23187 ( $\mathrm{Ca}^{2+}$-mobilizing agent). Here, the 5-LOX activity for endogenous arachidonic acid was assessed by RP-HPLC (Figure $1 \mathrm{~A}$ ).

A

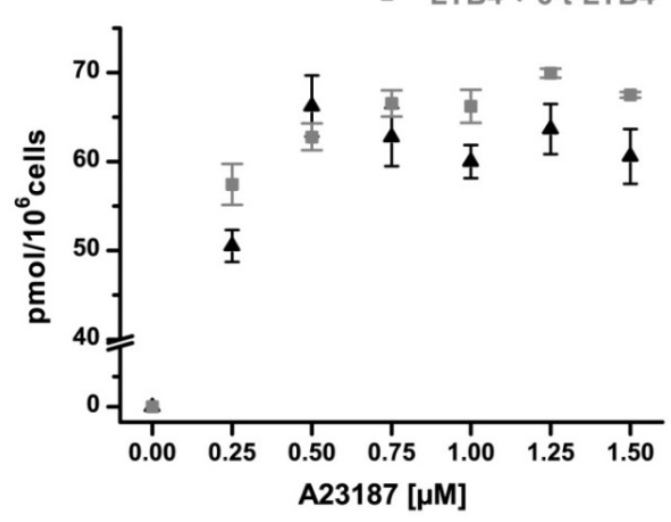

B

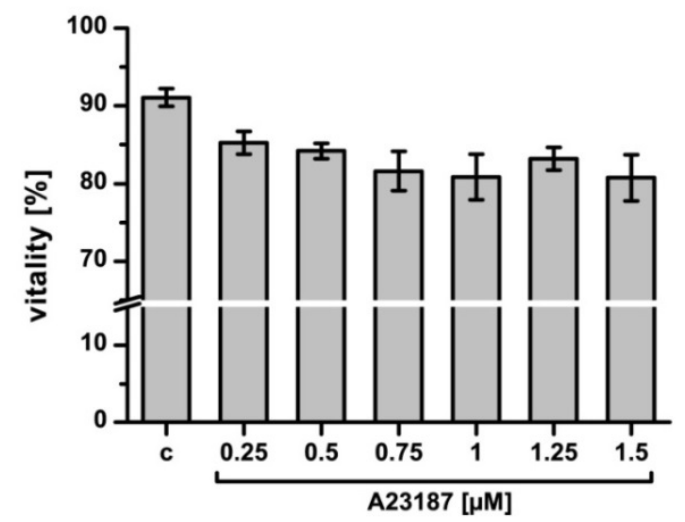

Figure 1: Stimulation of neutrophils with increasing concentrations of A23187. Neutrophils $\left(5 \times 10^{6}\right.$ cells $/ \mathrm{ml}$ in HBSS with $\mathrm{Ca2}+, \mathrm{pH} \mathrm{7.4)}$ were incubated at $37^{\circ} \mathrm{C}$ for $30 \mathrm{~min}$ and were subsequently stimulated with A23187 for 5 min. (A) 5-LOX product formation was determined by RP-HPLC $(n=3)$. (B) Vitality of unstimulated (control - C) and A23187-treated cells was assessed by JC-1 staining $(n=3)$.

In contrast to cell-free experiments with recombinant 5-LOX, where 5-HpETE and 6-trans$\mathrm{LTB}_{4}$ are the main products, neutrophils produced 5-HETE, the glutathione peroxidasecatalyzed reduction product of 5-HpETE, and a mixture of $\mathrm{LTB}_{4}+6$-trans-LTB 4 . In cellular experiments no 5-HpETE could be measured assuming that all 5-HpETE is reduced to 5-HETE during neutrophil activation. The LTB 4 is produced from LTA $\mathrm{L}_{4}$ by $\mathrm{LTA}_{4}$ hydrolase, whereas 6-trans-LTB ${ }_{4}$ (5S,12S/R-DiHETE) originates from non-enzymatic $\mathrm{LTA}_{4}$-hydrolysis. With increasing $A 23187$ concentrations a saturation of the 5-LOX product formation of 5-HETE and $\mathrm{LTB}_{4}+6$-trans- $\mathrm{LTB}_{4}$ was measured yielding around 130 pmol 5-LOX products per $1 \times 10^{6}$ cells, whereby similar amounts of 5-HETE and leukotrienes products were formed. The pre-incubation with the 5-LOX inhibitor BWA4C resulted in a complete diminution of 5-LOX product formation (data not shown). Furthermore, vitality of the neutrophils was determined using JC-1 staining (Figure 1 B). Due to A23187 stimulation a slight decrease in cell vitality to $80 \%$ compared to the unstimulated control with $90 \%$ vitality was observed. To ensure an effective 5-LOX activation, neutrophils were stimulated with $0.75 \mu \mathrm{M}$ A23187 in the subsequent experiments.

For optimal 5-LOX stimulation it became apparent that the incubation time of neutrophils with A23187 is a critical parameter. Both 5-LOX product composition (Figure 2 A) and cell vitality (Figure 2 B) showed drastic changes in dependence on the duration of A23187 stimulation. Especially, the amount of 5-HETE greatly decreased at longer stimulation. Furthermore, the amount of $\mathrm{LTB}_{4}$ was reduced after 20 min compared to the maximal concentration at $5 \mathrm{~min}$. The 6-trans- $\mathrm{LTB}_{4}$ concentration showed a constant increase at longer incubation times. Interestingly, the longer A23187 stimulation resulted in a considerable decline of cell vitality to $65 \%$ after $20 \mathrm{~min}$. To ensure a maximal formation of 
5-HETE and $\mathrm{LTB}_{4}$, cells were stimulated for 5 min with $0.75 \mu \mathrm{M} \mathrm{A23187}$ in the subsequent experiments.
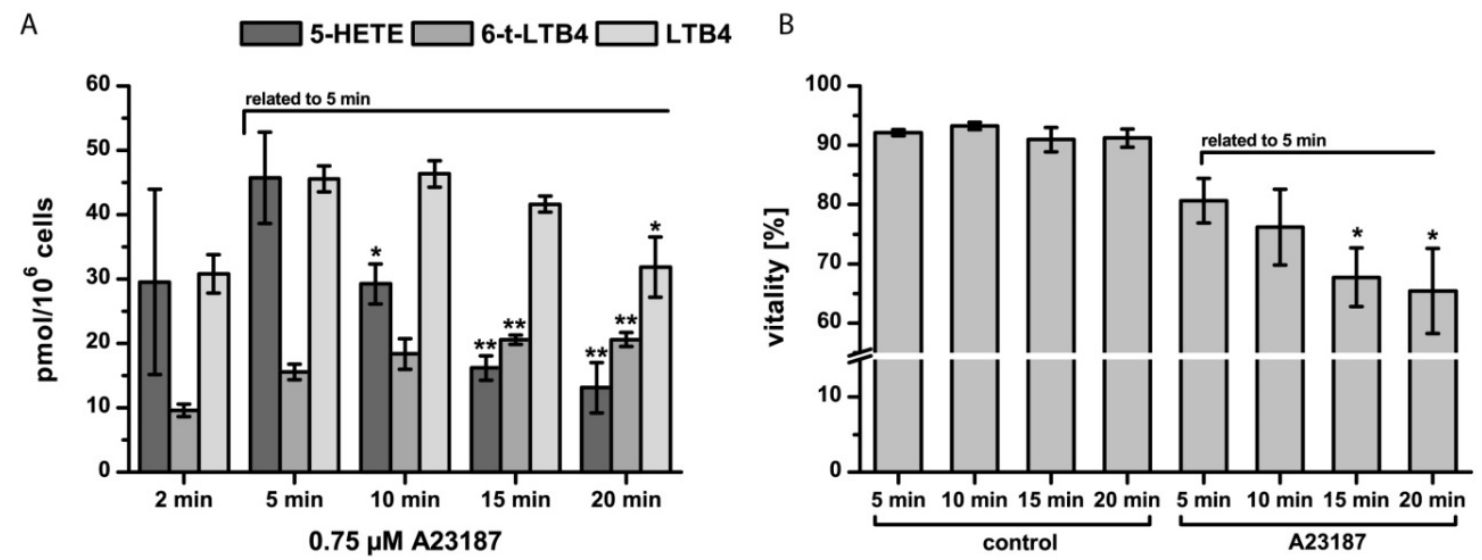

Figure 2: Stimulation of neutrophils with $\mathrm{A} 23187$ as a function of incubation time. Neutrophils $(5 \times$ $10^{6}$ cells $/ \mathrm{ml}$ in HBSS with $\mathrm{Ca}^{2+}, \mathrm{pH} 7.4$ ) were incubated at $37^{\circ} \mathrm{C}$ for $30 \mathrm{~min}$ and were subsequently stimulated with $0.75 \mu \mathrm{M}$ A23187 for $5-20 \mathrm{~min}$. (A) 5-LOX product formation was determined by RPHPLC $(n=3)$. (B) Vitality of unstimulated (control) and A23187-treated cells, differing in their incubation time, was assessed by JC-1 staining $(n=3)$. A two-tailed $t$ test $\left({ }^{*} p \leq 0.05 ;{ }^{* *} p \leq 0.01\right)$ was performed against the appropriate 5 min sample.

\section{Simultaneous stimulation of 5-LOX and MPO in neutrophils using $\mathrm{H}_{2} \mathrm{O}_{2}$ and A23187}

Neutrophils were stimulated by a direct supply of $\mathrm{H}_{2} \mathrm{O}_{2}$ to evaluate the effect of MPO on the 5-LOX activity. The permeability of extracellular added $\mathrm{H}_{2} \mathrm{O}_{2}$ across the neutrophil membrane is relatively high [Winterbourn et al. 2006], so it can be assumed that enough $\mathrm{H}_{2} \mathrm{O}_{2}$ can get inside the cell. A part of this intracellular amount of $\mathrm{H}_{2} \mathrm{O}_{2}$ could be decomposed by neutrophil catalase or further peroxidases [Roos et al. 1980], before reaching the MPO. For this reason the activity of MPO was measured under these conditions (Figure $3 \mathrm{~A}$ ) with the non-fluorescent dye APF yielding fluorescein after reaction with $\mathrm{HOCl}$ [Flemmig et al. 2012; Flemmig et al. 2015]. Here, the APF-derived fluorescence signal of $\mathrm{H}_{2} \mathrm{O}_{2}$-stimulated cells increased in comparison to A23187-stimulated cells. Thereby, $2 \mathrm{mM} \mathrm{H} \mathrm{O}_{2}$ enhanced the APF-derived fluorescence by 8.1-times compared to A23187-stimulated cells. Further controls with the MPO inhibitor 4-ABAH were considered for calculation of the ratio of APF fluorescence intensity of stimulated cells without 4-ABAH compared to 4-ABAH treated cells. This was necessary because also hydroxyl radicals or peroxynitrite could oxidize APF [Setsukinai et al. 2003]. Interestingly, the ratio of APF fluorescence in the absence and presence of 4-ABAH revealed in A23187-stimulated cells without the addition of $\mathrm{H}_{2} \mathrm{O}_{2}$ a 6.2-fold MPO-induced APF increase (Figure $3 \mathrm{~B}$ ). Indeed, addition of $\mathrm{H}_{2} \mathrm{O}_{2}$ resulted in considerable rise of the MPO-induced APF response. For example, cells treated with $1.5 \mathrm{mM} \mathrm{H}_{2} \mathrm{O}_{2}$ showed a 3.3-times higher MPO-induced APF response compared to the $\mathrm{A} 23187$ control (Figure $3 \mathrm{~B}$ ). Also the vitality of $\mathrm{H}_{2} \mathrm{O}_{2}$-stimulated cells was examined (Figure $3 \mathrm{C}$ ). Even the highest applied $\mathrm{H}_{2} \mathrm{O}_{2}$ concentration did not significantly reduce the neutrophil vitality. 

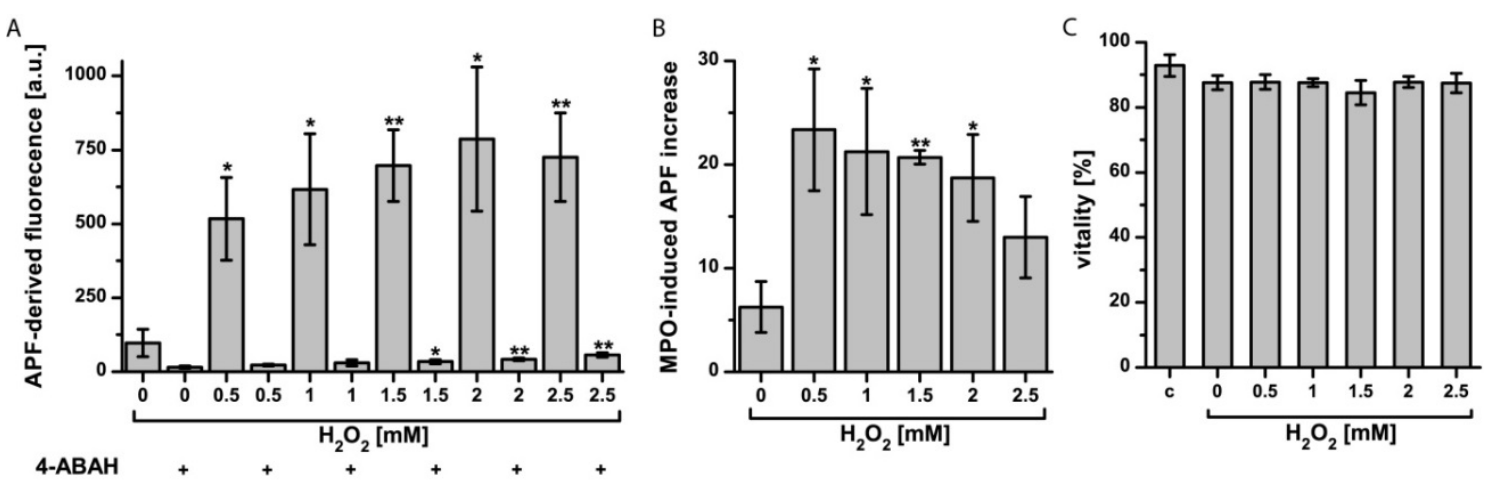

Figure 3: Determination of MPO activity and cell vitality in A23187- and $\mathrm{H}_{2} \mathrm{O}_{2}$-stimulated neutrophils. Neutrophils $\left(5 \times 10^{6}\right.$ cells $/ \mathrm{ml}$ in HBSS with $\left.\mathrm{Ca}^{2+}, \mathrm{pH} 7.4,37^{\circ} \mathrm{C}\right)$ were incubated with and without $2.5 \mathrm{mM}$ 4-ABAH for $15 \mathrm{~min}$. Afterwards, cells were stained with $10 \mu \mathrm{M}$ APF for $15 \mathrm{~min}$ and stimulated with $\mathrm{H}_{2} \mathrm{O}_{2}$ for 20 min. During the last 5 min $\mathrm{A} 23187(0.75 \mu \mathrm{M})$ was added in all samples. For cell vitality (C) APF staining was omitted. Samples were washed with HBSS without $\mathrm{Ca}^{2+}$ and analyzed by flow cytometry. (A) APF-derived fluorescence intensity of A23187-treated sample and $\mathrm{H}_{2} \mathrm{O}_{2}+$ A23187-stimulated cells were measured $(n=3)$. (B) The ratio of APF fluorescence intensity of stimulated cells without 4-ABAH to 4-ABAH treated cells was calculated. (C) Cell vitality of unstimulated (control - c) and A23187- and $\mathrm{H}_{2} \mathrm{O}_{2}+\mathrm{A} 23187$-stimulated cells was assessed by JC-1 staining $(n=3)$. A two-tailed $t$ test $(* p \leq 0.05 ; * * p \leq 0.01)$ was performed against A23187 or A23187+4-ABAH.

In the next step, the activity of 5-LOX was measured under these conditions (Figure 4). Interestingly, increasing concentrations of $\mathrm{H}_{2} \mathrm{O}_{2}$ led to a slightly increase in 5-HETE. For example applying $2 \mathrm{mM} \mathrm{H}_{2} \mathrm{O}_{2}$ resulted in 1.22-fold higher 5-HETE concentration (Figure 4 A). In contrast, the same amount of $\mathrm{H}_{2} \mathrm{O}_{2}$ reduced the formation of $\mathrm{LTB}_{4}$ and 6-trans- $\mathrm{LTB}_{4}$ to $44 \%$ and $37 \%$, respectively (Figure $4 \mathrm{~B}$ ). The inhibition of MPO by $4-\mathrm{ABAH}$ clearly showed that the $\mathrm{H}_{2} \mathrm{O}_{2}$-induced increase in 5-HETE depends on the MPO-activity. Because, in the presence of 4-ABAH there was $50 \%$ lower amounts of 5-HETE in neutrophils stimulated with $2 \mathrm{mM} \mathrm{H} \mathrm{O}_{2}$. For unstimulated neutrophils a part of the amount of 5-HETE (30\%) also depended on the MPO activity. This is in line with the detected MPO activity in A23187stimulated cells assessed by APF staining (Figure $3 \mathrm{~B}$ ).

These results reflect properly the in vitro experiments, where MPO-derived oxidants showed a considerable impact on recombinant human 5-LOX, impairing the epoxidation of 5-HpETE, whereas the hydroperoxidation of arachidonic acid was unaffected [Zschaler et al. 2015]. Unfortunately, a direct effect of MPO on the $\mathrm{H}_{2} \mathrm{O}_{2}$-mediated reduction of $\mathrm{LTB}_{4}$ could not be evaluated using 4-ABAH (Figure $4 \mathrm{~B}$ ). Only for the neutrophil stimulation with $0.5 \mathrm{mM} \mathrm{H}_{2} \mathrm{O}_{2}$ a $16 \%$ higher $\mathrm{LTB}_{4}$ amount was measured indicating a weak MPO-induced $\mathrm{LTB}_{4}$-reduction, which was abrogated after 4-ABAH treatment. However, in the other samples no influence of 4-ABAH treatment occurred. This could be interpreted by a $\mathrm{H}_{2} \mathrm{O}_{2-}$ driven inhibition of 5-LOX activity. In previous experiments the incubation of recombinant 5-LOX with $\mathrm{H}_{2} \mathrm{O}_{2}$ also diminished its activity [Zschaler et al. 2015]. However, this does not explain why the 5-HETE concentration was unaffected. Therefore the reduction of $\mathrm{LTB}_{4}$ could be a superimposition of a $\mathrm{H}_{2} \mathrm{O}_{2}$ effect inhibiting 5-LOX and a MPO-driven $\mathrm{HOCl}$ effect on 5-LOX yielding to a reduction of the amount of $\mathrm{LTB}_{4}$ and 6-trans-LTB 4 , while the amount of 5-HETE slightly increased. Thus, in the presence of the MPO inhibitor 4-ABAH the reduction of $\mathrm{LTB}_{4}$ is caused by $\mathrm{H}_{2} \mathrm{O}_{2}$. This could be compared with further in vitro 
experiments, where both human MPO and 5-LOX, were co-incubated, and a $\mathrm{H}_{2} \mathrm{O}_{2}$ generating system activated the peroxidase [Zschaler et al. 2015].

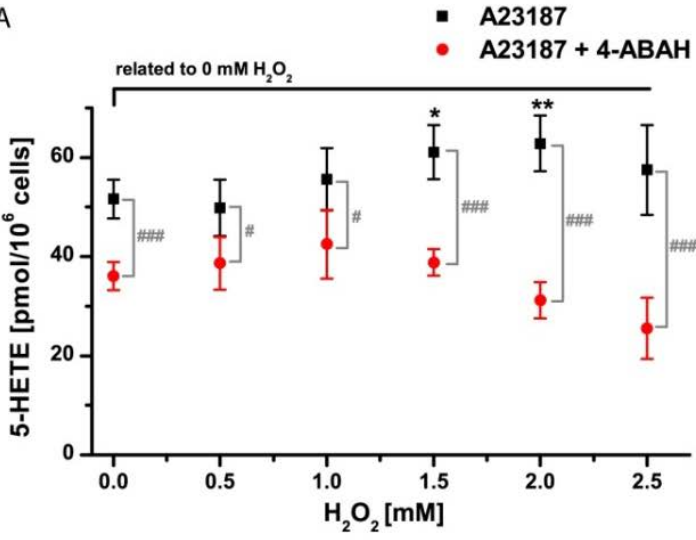

C

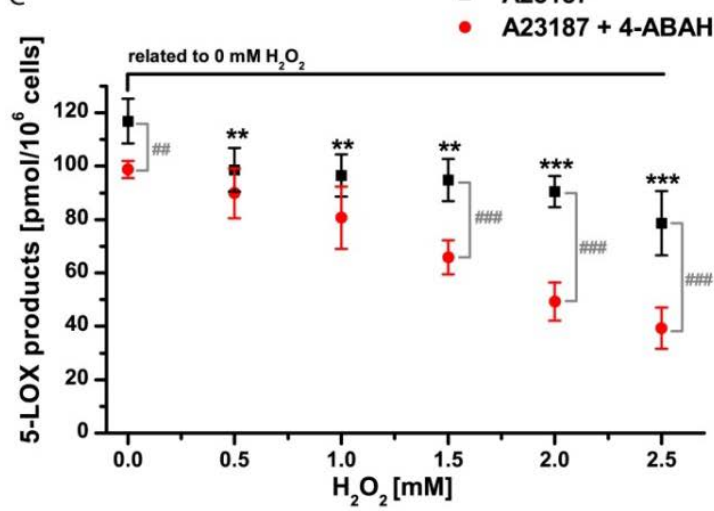

B

$\mathrm{LTB}_{4}:$ - A23187 $-\mathrm{A} 23187+4-\mathrm{ABAH}$

$6-t-\mathrm{LTB}_{4}:-\mathrm{A} 23187>\mathrm{A} 23187+4-\mathrm{ABAH}$

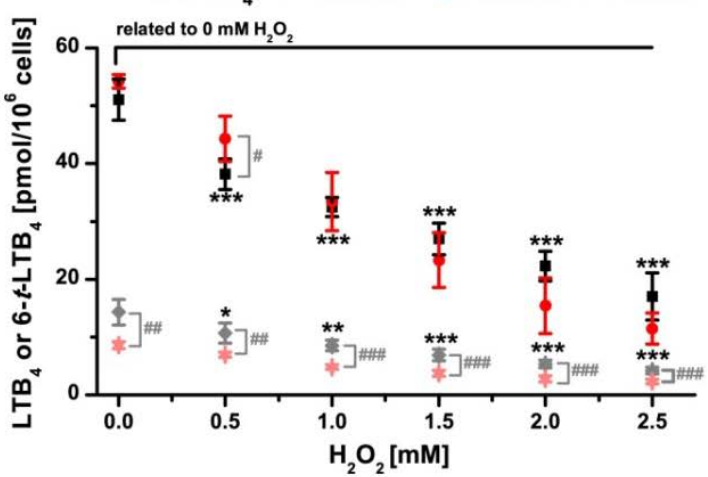

D $\quad$ - A23187

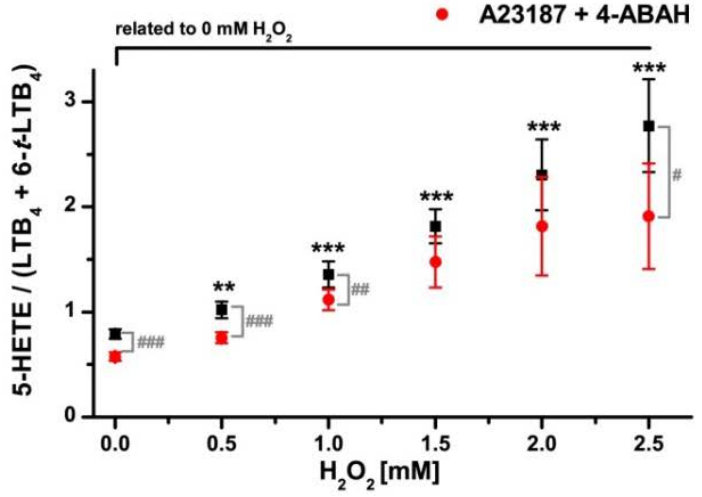

Figure 4: Stimulation of neutrophils with $\mathrm{A} 23187$ and $\mathrm{H}_{2} \mathrm{O}_{2}$ for simultaneous activation of 5-LOX and MPO. Neutrophils $\left(5 \times 10^{6}\right.$ cells $/ \mathrm{ml}$ in HBSS with $\left.\mathrm{Ca}^{2+}, \mathrm{pH} 7.4,37^{\circ} \mathrm{C}\right)$ were incubated with and without $2.5 \mathrm{mM}$ 4-ABAH for $15 \mathrm{~min}$. Afterwards cells were stimulated with $\mathrm{H}_{2} \mathrm{O}_{2}$ for 20 min and during the last 5 min A23187 $(0.75 \mu \mathrm{M})$ was added. The amount of 5-HETE (A), LTB 4 or 6-trans-LTB 4 (B) and total 5-LOX product formation (C) was determined by RP-HPLC ( $n=4-6)$. Furthermore, the ratio of 5-HETE to the sum of $\mathrm{LTB}_{4}+6$-trans- $\mathrm{LTB}_{4}$ (D) was related to the applied $\mathrm{H}_{2} \mathrm{O}_{2}$ concentration. A two-tailed $t$ test was performed. Grey hashtags indicate the correlation of samples with and without inhibitor 4-ABAH (\# $\mathrm{p} \leq 0.05$; \#\# $\mathrm{p} \leq 0.01$; \#\#\# $\mathrm{p} \leq 0.001$ ). Black asterisks indicate the correlation of the $\mathrm{H}_{2} \mathrm{O}_{2}$ treated samples without inhibitor to the untreated sample without $\mathrm{H}_{2} \mathrm{O}_{2}$ (* $\mathrm{p} \leq 0.05$; ** $\mathrm{p} \leq 0.01$; *** $\mathrm{p} \leq 0.001)$.

In considering an effect of 4-ABAH on the amount of 6-trans-LTB 4 a decrease after MPO inhibition was present, albeit in a relatively low quantity compared to the overall 5-LOX product amount. This could be explained in part with higher availability of $\mathrm{H}_{2} \mathrm{O}_{2}$ in case of MPO inhibition, yielding a stronger effect after 4-ABAH treatment.

In addition, the whole 5-LOX activity was summarized after MPO stimulation (Figure $4 \mathrm{C}$ ). The stimulation with $\mathrm{H}_{2} \mathrm{O}_{2}$ resulted in a maximal decrease of $33 \%$ of 5 -LOX product formation, whereas in 4-ABAH treated samples, $\mathrm{H}_{2} \mathrm{O}_{2}$ induced a maximal decline of $60 \%$. As shown above this decrease is due to the drastic reduction of $\mathrm{LTB}_{4}$ and 6 -trans- $\mathrm{LTB}_{4}$. This is also reflected in a strong rise of the ratio of 5-HETE to the sum of LTB 4 + 6-trans-LTB $B_{4}$ also increasing after MPO inhibition, however, to a lower extent (Figure 4 D). Control experiments with solely $\mathrm{H}_{2} \mathrm{O}_{2}$-treated neutrophils without the addition of A23187 revealed no 5-LOX activity (data not shown). 
The stimulation of neutrophils with $\mathrm{H}_{2} \mathrm{O}_{2}$, under consideration of cell vitality and MPO activity, changed the product profile of 5-LOX, leading to the dominance of 5-HETE in relation of $\mathrm{LTB}_{4}$ and 6 -trans- $\mathrm{LTB}_{4}$. This became apparent in the increased formation of 5-HETE after MPO activation in dependence on 4-ABAH addition. For $\mathrm{LTB}_{4}$ and 6-trans-LTB a MPO-induced reduction could not be clearly shown, possibly due to a superimposition with a $\mathrm{H}_{2} \mathrm{O}_{2}$-mediated inhibition of 5-LOX activity. Especially in the presence of 4-ABAH, which disturbs the clearance of external supplied $\mathrm{H}_{2} \mathrm{O}_{2}$ by neutrophil MPO.

\section{Simultaneous stimulation of 5-LOX and MPO in neutrophils using PMA and A23187}

Besides the direct supply of $\mathrm{H}_{2} \mathrm{O}_{2}$, the MPO can also be activated by initiation of the respiratory burst. As a further neutrophil stimulant PMA was used. PMA is a known activator of protein kinase $C$ and is able to increase reactive oxygen species (ROS) production in neutrophils by NADPH oxidase stimulation [Nauseef et al. 1991]. First of all the MPO activity was measured under these conditions with APF (Figure 5).
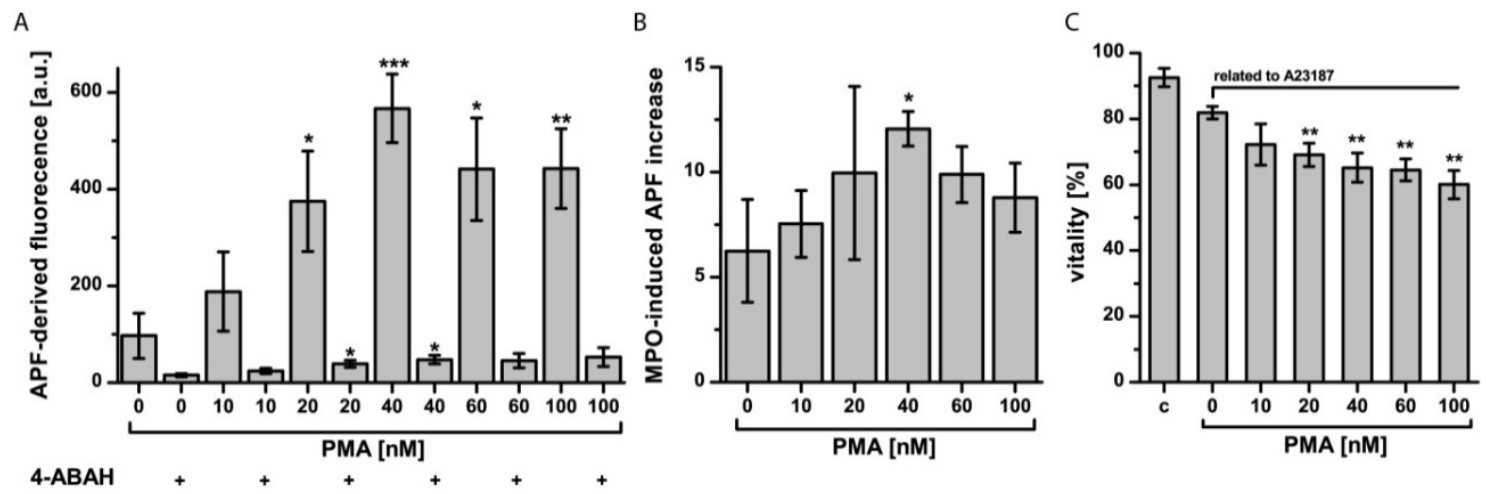

Figure 5: Determination of MPO activity and cell vitality in A23187- and PMA-stimulated neutrophils. Neutrophils $\left(5 \times 10^{6}\right.$ cells $/ \mathrm{ml}$ in HBSS with $\left.\mathrm{Ca}^{2+}, \mathrm{pH} 7.4,37^{\circ} \mathrm{C}\right)$ were incubated with and without $2.5 \mathrm{mM}$ 4-ABAH for $15 \mathrm{~min}$. Afterwards, cells were stained with $10 \mu \mathrm{M}$ APF for 15 min and stimulated with PMA for 20 min. During the last 5 min A23187 (0.75 $\mu \mathrm{M})$ was added in all samples. For cell vitality (C) APF staining was omitted. Samples were washed with $\mathrm{HBSS}$ without $\mathrm{Ca}^{2+}$ and analyzed by flow cytometry. (A) APF-derived fluorescence intensity of A23187-treated sample and PMA+A23187-stimulated cells were measured $(n=3)$. (B) The ratio of APF fluorescence intensity of stimulated cells without $4-A B A H$ to $4-A B A H$ treated cells was calculated. (C) Cell vitality of unstimulated (control - c) and A23187- and PMA+A23187-stimulated cells was assessed by JC-1 staining $(n=3)$. A two-tailed $t$ test $\left(* p \leq 0.05 ;{ }^{* *} p \leq 0.01 ; * * * p \leq 0.001\right)$ was performed against A23187 or A23187+4-ABAH.

Here, PMA (40 nM) strongly enhanced the APF-derived fluorescence signal by 5.7-times compared to the sole A23187-treated control (Figure 5 A). However, further controls with the MPO inhibitor 4-ABAH were considered for calculation of the ratio of APF fluorescence intensity of stimulated cells without 4-ABAH to 4-ABAH treated cells. This MPO-induced APF response revealed only a two-fold increase after stimulation with $40 \mathrm{nM}$ PMA compared to the A23187-treated control (Figure 5 B). Higher PMA concentrations did not result in a stronger MPO-activation. Under these harsh conditions, we cannot exclude the formation of hydroxyl radicals, which are also capable to react with APF [Setsukinai et al. 2003]. Higher amounts of PMA were not applied, because already 100 nM PMA led to a strong decline of cell vitality (Figure $5 \mathrm{C}$ ). In this case, only $60 \%$ vital cells were determined. 
Subsequently, the activity of 5-LOX was measured under these conditions. Control experiments were performed with cells stimulated with PMA alone or the used vehicle DMSO. In both cases there was no 5-LOX activity (data not shown).

The treatment of neutrophils with increasing concentrations of PMA resulted in a drastic decline of the amount of 5-HETE (Figure 6 A).

A

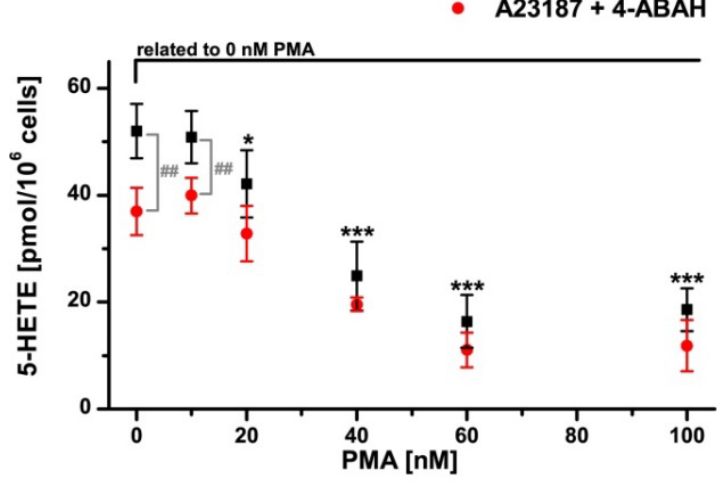

C

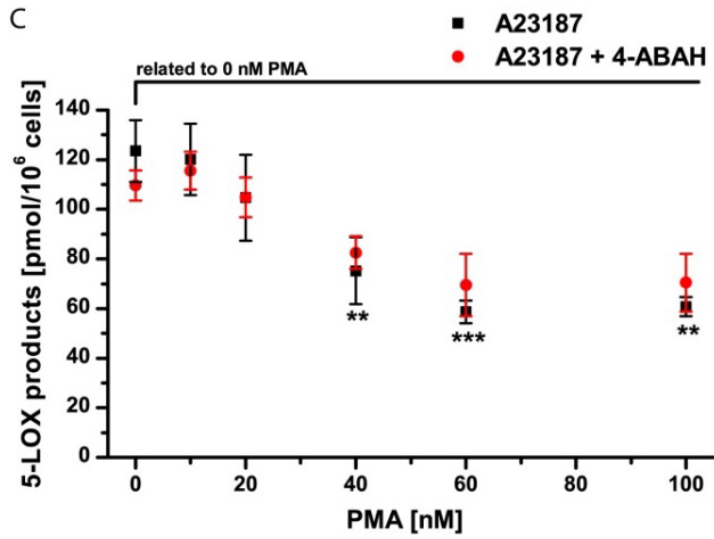

B $\quad$ LTB $_{4}:=\mathrm{A} 23187-\mathrm{A} 23187+4-\mathrm{ABAH}$ $6-t-$ LTB $_{4}:-A 23187$ - A23187 + 4-ABAH

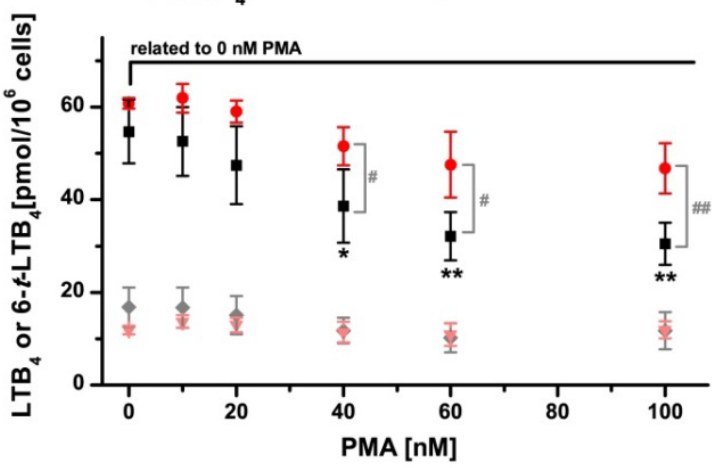

D $\quad$ - A23187

- A23187 + 4-ABAH

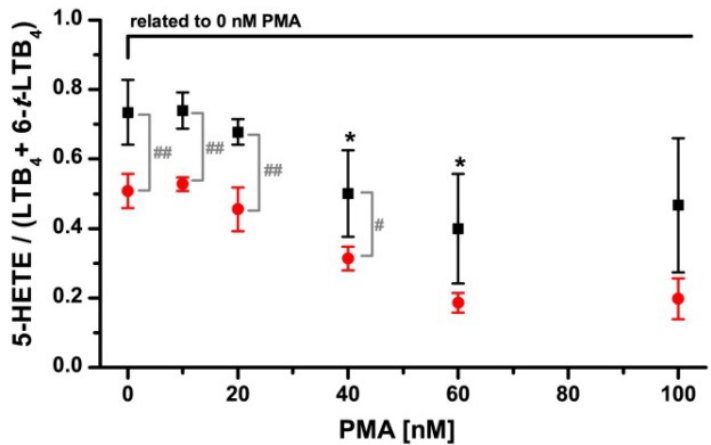

Figure 6: Stimulation of neutrophils with A23187 and PMA for simultaneous activation of 5-LOX and MPO. Neutrophils $\left(5 \times 10^{6}\right.$ cells $/ \mathrm{ml}$ in $\mathrm{HBSS}$ with $\left.\mathrm{Ca}^{2+}, \mathrm{pH} 7.4,37^{\circ} \mathrm{C}\right)$ were incubated with and without $2.5 \mathrm{mM}$ 4-ABAH for $15 \mathrm{~min}$. Afterwards cells were stimulated with PMA for $20 \mathrm{~min}$ and during the last 5 min A23187 $(0.75 \mu \mathrm{M})$ was added. The amount of 5-HETE (A), LTB 4 or 6-trans-LTB 4 (B) and total 5-LOX product formation (C) was determined by RP-HPLC $(n=3-4)$. Furthermore, the ratio of 5-HETE to the sum of $\mathrm{LTB}_{4}+6$-trans-LTB 4 (D) was related to the applied PMA concentration. A two-tailed $t$ test was performed. Grey hashtags indicate the correlation of samples with and without inhibitor 4-ABAH (\# $\mathrm{p} \leq 0.05$; \#\# $\mathrm{p} \leq 0.01$ ). Black asterisks indicate the correlation of the PMA-treated samples without inhibitor to the untreated sample without PMA (*p $\leq 0.05 ; * * p \leq 0.01 ; * * p \leq 0.001)$.

Here, for example the stimulation with 60 nM PMA led to 68\% lower concentrations of 5-HETE. The amount of $\mathrm{LTB}_{4}$ (Figure $6 \mathrm{~B}$ ) was only reduced by $41 \%$ after application of $60 \mathrm{nM}$ PMA. The inhibition of MPO by 4-ABAH has two different consequences. The 5-HETE producing activity was reduced by 4-ABAH in the A23187-treated sample and in cells stimulated with 10 nM PMA. However, the drastic PMA-induced decrease in 5-HETE was not affected by MPO inhibition. In contrast, higher amounts of $\mathrm{LTB}_{4}$ were detected when MPO was inhibited and neutrophils were stimulated with PMA. Whereby, the $\mathrm{LTB}_{4}$ concentration increased by $50 \%$, when cells were treated with $4-\mathrm{ABAH}$ and subsequently stimulated with 60-100 nM PMA. For 6-trans-LTB 4 no PMA or 4-ABAH effect was observed (Figure 6 B). 
Comparing the stimulation of neutrophils with PMA and $\mathrm{H}_{2} \mathrm{O}_{2}$ regarding the 5-LOX activity revealed drastic differences. PMA resulted in an abrogation of the partially MPO-mediated production of 5-HETE in unstimulated cells due to the strong decrease in the amount of 5-HETE clearly distinguishing it from the stimulant $\mathrm{H}_{2} \mathrm{O}_{2}$ used for MPO activation. On that basis it is striking that the $\mathrm{LTB}_{4}$ reduction after PMA stimulation depended on the MPO activity. Here, higher amounts of $\mathrm{LTB}_{4}$ were seen in 4-ABAH-treated neutrophils. It could be assumed, that active MPO reduced the production of $\mathrm{LTB}_{4}$ after PMA stimulation. As mentioned above the stimulation with PMA resulted in a gradual impairment of cell vitality (Figure $5 \mathrm{C}$ ). A partial impairment of 5-LOX activity due to reduced cell functionality could be assumed.

Reflecting the total 5-LOX product formation a strong decrease of $50 \%$ was observed after application of $100 \mathrm{nM}$ PMA (Figure $6 \mathrm{C}$ ). The addition of 4-ABAH had no influence on the overall extent of 5-LOX products. However, the ratio of 5-HETE to the sum of $\mathrm{LTB}_{4}+6$-trans$\mathrm{LTB}_{4}$ was changed in consequence of 4-ABAH (Figure $6 \mathrm{D}$ ). Both the A23187-treated sample and cells stimulated with low PMA concentrations showed a reduced ratio of 5-HETE to the sum of $\mathrm{LTB}_{4}+6$-trans-LTB 4 when MPO activity was suppressed with 4-ABAH due to the possibly MPO-mediated formation of 5-HETE in unstimulated cells. In addition, $40 \mathrm{nM}$ and $60 \mathrm{nM}$ PMA led to a reduction of the ratio of 5-HETE to the sum of $\mathrm{LTB}_{4}+6$-trans-LTB 4 reflecting the dominance of $\mathrm{LTB}_{4}$ in PMA-stimulated neutrophils. The addition of 4-ABAH to cells stimulated with PMA in the range between 40 and $100 \mathrm{nM}$ resulted in a decrease in the ratio of 5-HETE to the sum of $\mathrm{LTB}_{4}+6$-trans- $\mathrm{LTB}_{4}$, albeit with low significance.

\section{Quantification of total glutathione}

In the presence of active 5-LOX the stimulation of neutrophils with $\mathrm{H}_{2} \mathrm{O}_{2}$ or PMA revealed different changes of 5-LOX product spectrum. Both stimulants were primarily used for MPO-activation. To explore the accompanying alteration of the neutrophil redox state, the amount of oxidized and reduced GSH was determined (Figure 7). Here, in unstimulated sample 900 pmol per $1 \times 10^{6}$ cells total glutathione were measured composed of oxidized and reduced GSH comparable to previous reports [Graham et al. 2009]. However, there was no GSSG detected, possibly too low concentrations were present. According to the standard curve the lowest measurable GSSG concentration was 80 pmol per $1 \times 10^{6}$ cells.

The stimulation with A23187 led to a reduction of total glutathione to 690 pmol. The further addition of PMA resulted in a decrease of $40 \%$ compared to the A23187 stimulated cells. However, there was no dependence on PMA concentration. The treatment with $\mathrm{H}_{2} \mathrm{O}_{2}$ revealed a lower impact on total glutathione. In case of $0.5 \mathrm{mM} \mathrm{H}_{2} \mathrm{O}_{2}$ no significant changes were apparent. Only $1.5 \mathrm{mM}$ or $2.5 \mathrm{mM} \mathrm{H}_{2} \mathrm{O}_{2}$ resulted in reduction of $20 \%$ of total glutathione. Despite the loss of GSH both stimulants PMA and $\mathrm{H}_{2} \mathrm{O}_{2}$ did not increase the amount of GSSG assuming the presence of further GSH oxidation products.

It can be summarized that neutrophil stimulation with PMA lead to more drastic changes of redox status than $\mathrm{H}_{2} \mathrm{O}_{2}$. A reduction of GSH could have the consequence of a reduced activity of glutathione peroxidase $(\mathrm{GpX})$ and an impaired reduction of 5-HpETE to 5-HETE. This in turn elucidates why the amount of $\mathrm{LTB}_{4}$ was reduced to a lower extent. However the PMA induced changes of 5-LOX activity cannot be solely explained with variation in total glutathione. A reduced activity of glutathione peroxidase was also associated with a higher hydroperoxide tone, which is essential for 5-LOX activation [Hatzelmann et al. 1989]. 
Nevertheless, the different behavior of PMA and $\mathrm{H}_{2} \mathrm{O}_{2}$ regarding 5-LOX product profile could be partially related to the neutrophil redox status.

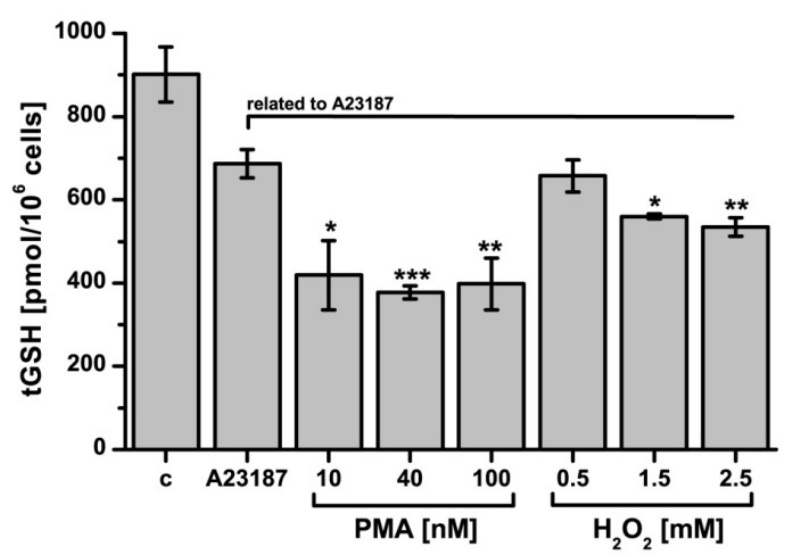

Figure 7: Determination of total glutathione (tGSH) amount in stimulated cells. Neutrophils $\left(5 \times 10^{6}\right.$ cells $/ \mathrm{ml}$ in HBSS with $\mathrm{Ca}^{2+}, \mathrm{pH}$ 7.4) were incubated at $37^{\circ} \mathrm{C}$ for $15 \mathrm{~min}$. Afterwards cells were stimulated with PMA or $\mathrm{H}_{2} \mathrm{O}_{2}$ for 20 min. During the last 5 min A23187 (0.75 $\left.\mu \mathrm{M}\right)$ was added. All incubation steps were performed at $37{ }^{\circ} \mathrm{C}$. Samples were washed with HBSS without $\mathrm{Ca}^{2+}$ and total glutathione of unstimulated (control - c) and A23187- and $\mathrm{H}_{2} \mathrm{O}_{2}$ - or PMA-stimulated cells were measured $(n=3)$. A two-tailed $t$ test $(* p \leq 0.05 ; * * p \leq 0.01 ; * * * p \leq 0.001)$ was performed against A23187. 


\section{Discussion and conclusion}

The simultaneous activation of MPO and 5-LOX in neutrophils revealed an effect of MPO on the 5-LOX product formation differing in the applied cell stimulant. In this study, special attention was drawn to cell vitality assessed by the dye JC-1 serving as an early marker for changes in the mitochondrial potential. An incubation of neutrophils with the $\mathrm{Ca}^{2+}$ ionophore $\mathrm{A} 23187(0.75 \mu \mathrm{M})$ for more than $10 \mathrm{~min}$ resulted in a considerable decrease in cell vitality and reduced formation of specific 5-LOX products. Thus, we choose an incubation time of $5 \mathrm{~min}$ with A23187 $(0.75 \mu \mathrm{M})$ for most experiments. Under these conditions at least $80 \%$ vital cells were detected. Our experiments revealed a comparable amount of 5-LOX products as previously reported applying $2.5 \mu \mathrm{M}$ A23187 for 5 min [Werz et al. 2002]. The $\mathrm{Ca}^{2+}$ ionophore $\mathrm{A} 23187$ increased the cytoplasmic $\mathrm{Ca}^{2+}$ level, and favors, thus, the translocation of 5-LOX to the nuclear envelope [Werz et al. 2002]. Furthermore, elevated $\mathrm{Ca}^{2+}$ concentrations regulate the activity of $\mathrm{CPLA}_{2}$ activity [Gijon and Leslie 1999], a critical step for stimulus dependent AA mobilization. The 5-LOX activity on endogenous AA was sufficient for assessment of 5-LOX product formation in our case. In contrast, the combined addition of exogenous AA $(20-40 \mu \mathrm{M})$ and A23187 was accompanied by a reduced cell vitality and a higher yield of 5-HETE compared to LTB $_{4}$ fractions (unpublished data).

Application of external $\mathrm{H}_{2} \mathrm{O}_{2}$ for MPO activation has several consequences on 5-LOX product formation by neutrophils. First of all, there was a considerable increase in the ratio of 5-HETE to the sum of $\mathrm{LTB}_{4}+6$-trans-LTB $\mathrm{L}_{4}$ with increasing $\mathrm{H}_{2} \mathrm{O}_{2}$ concentrations. On the one hand, this was caused mainly by the drop of both $\mathrm{LTB}_{4}$ fractions. On the other hand, 5-HETE increased slightly under these conditions. The inhibition of MPO reduced most of all the level of 5-HETE, whereby the effect increased with higher amounts of $\mathrm{H}_{2} \mathrm{O}_{2}$. It could be assumed that MPO metabolites mainly impair the epoxidation reaction of 5 - $\mathrm{HpETE}$ in comparison to the hydroperoxidation reaction of AA. Similar observations were previously obtained for the effect of $\mathrm{HOCl}$ and $\mathrm{HOBr}$ on recombinant 5-LOX [Zschaler et al. 2015].

However, it should be stressed that inhibition of MPO did not counteract the overall decrease in $\mathrm{LTB}_{4}+6$-trans- $\mathrm{LTB}_{4}$. Although, for $\mathrm{LTB}_{4}$ there was a slight increase at low $\mathrm{H}_{2} \mathrm{O}_{2}$, in the presence of higher $\mathrm{H}_{2} \mathrm{O}_{2}$ no significant changes were detected. For 6-trans- $\mathrm{LTB}_{4}$ there was a diminution in concentration. According to our previous results of recombinant human 5-LOX incubated with the MPO- $\mathrm{H}_{2} \mathrm{O}_{2}-\mathrm{Cl}^{-}$system [Zschaler et al. 2015] a superimposition of a MPO-driven $\mathrm{HOCl}$ effect on 5-LOX, resulting in a reduction of the product formation of $\mathrm{LTB}_{4}$ and 6-trans- $\mathrm{LTB}_{4}$, and a $\mathrm{H}_{2} \mathrm{O}_{2}$-mediated inhibition of 5-LOX activity, could be assumed. In neutrophils, $\mathrm{H}_{2} \mathrm{O}_{2}$ is mainly consumed by catalase, myeloperoxidase, and $\mathrm{GpX}$. The inhibition of MPO by 4-ABAH enhanced considerably the $\mathrm{H}_{2} \mathrm{O}_{2}$-mediated decrease in 5-LOX products. This was obvious in the further decrease in 6-trans- $\mathrm{LTB}_{4}$ after 4-ABAH treatment. In the previous study [Zschaler et al. 2015] the recombinant 5-LOX was incubated with a glucose oxidase-glucose (GOD-Glu)-system producing $\mathrm{H}_{2} \mathrm{O}_{2}$ for MPO activation revealing a $\mathrm{HOCl}$-mediated effect on 5-LOX product formation. However, in the absence of the MPO substrate $\mathrm{Cl}^{-}, \mathrm{H}_{2} \mathrm{O}_{2}$ generated by GOD-Glu system inhibited 5-LOX [Zschaler et al. 2015]. These in vitro experiments revealed comparable results to the observed product changes of 5-LOX in neutrophils after simultaneous activation of MPO. An impact of MPO products on $\mathrm{LTA}_{4}$ hydrolase activity is also possible, influencing the ratio of 6-trans-LTB $\mathrm{LT}_{4}$ to $\mathrm{LTB}_{4}$. However, more detailed investigations are necessary to draw a final conclusion. It can be concluded that the activation of MPO by $\mathrm{H}_{2} \mathrm{O}_{2}$ increased the 5-HETE formation and changed

Prostaglandins, Leukotrienes and Essential Fatty Acids (PLEFA), provided by University Library Leipzig [2017] 
the product ratio of 5-LOX with lower $\mathrm{LTB}_{4}+6$-trans- $\mathrm{LTB}_{4}$ formation comparable to the incubation of MPO and 5-LOX in in vitro experiments.

In order to further clarify this point, PMA was used as MPO stimulant. Here, varying 5-LOX product changes appeared as described for $\mathrm{H}_{2} \mathrm{O}_{2}$. The most marked difference was the strong reduction of 5-HETE formation observed at PMA concentrations higher than $20 \mathrm{nM}$. Effects caused by MPO were less expressed in comparison to $\mathrm{H}_{2} \mathrm{O}_{2}$. There was a slightly lower formation of 5-HETE in unstimulated cells after MPO inhibition. However, increasing PMA concentrations diminished this MPO effect. The amount of $\mathrm{LTB}_{4}$ was also reduced in PMA-treated neutrophils, albeit to a lower extent compared to 5-HETE implying the reduced ratio of 5-HETE to the sum of $\mathrm{LTB}_{4}+6$-trans- $\mathrm{LTB}_{4}$. Interestingly, the formation of $\mathrm{LTB}_{4}$ depended on the activity of MPO after stimulation with higher PMA concentrations. It could be assumed that, in this case, a HOCl-mediated effect is only obvious for $\mathrm{LTB}_{4}$, whereas a further MPO-independent process diminished the amount of 5-HETE. Oxidative stress could induce the oxidation of 5-HETE to 5-oxo-6E,8Z,11Z,14Z-eicosatetraenoic acid (5-oxo-ETE) by a dehydrogenase [Graham et al. 2009; Powell and Rokach 2013]. However, we detected no increase in 5-oxo-ETE formation, hence an oxidation of 5-HETE can be excluded. The quantification of the $\mathrm{LTB}_{4} \omega$-oxidation products, $20-\mathrm{OH}-\mathrm{LTB}_{4}$ and $20-\mathrm{COOH}-$ $\mathrm{LTB}_{4}$ emerging as further minor products, was not possible. Indeed, the qualitative assessment of this double peak revealed no influence after MPO inhibition with 4-ABAH. The different effect of MPO inhibition on 6-trans-LTB 4 and $\mathrm{LTB}_{4}$, both generated from $\mathrm{LTA}_{4}$, cannot be explained. Again, a modulation of the LTA ${ }_{4}$ hydrolase activity cannot be excluded.

The differences of PMA and $\mathrm{H}_{2} \mathrm{O}_{2}$ stimulation in relation to 5-LOX product formation were further assessed in the light of the redox status by means of total glutathione quantification. The amount of total glutathione decreased after stimulation with A23187. The additional presence of $\mathrm{H}_{2} \mathrm{O}_{2}$ resulted only in minor changes, whereas PMA reduced total glutathione to greater extent. An associated increase in oxidized GSSG was not detected. Graham et al. determined a comparable amount of GSH in unstimulated human neutrophils, while in aging neutrophils half of GSH was measured and 3\% GSSG was present [Graham et al. 2009]. This reduction of GSH was comparable to the stimulation with PMA in our experiments. Therefore, it can be assumed that these low changes of GSSG are below the detection limit of the applied method. The loss of GSH can be attributed to the formation of further oxidation products in addition to GSSG that will be not detected by the assay system. Furthermore, PMA was shown to induce GSH-S-thiolation of human neutrophil proteins during respiratory burst contributing to reduced GSH level [Chai et al. 1994].

The reduced amount of GSH could result in a lower activity of $\mathrm{GpX}$ and a reduced formation of 5-HETE from 5-HpETE. Accordingly, the higher level of 5-HpETE can serve as an activator of 5-LOX, and can favor the epoxidation reaction. We really observed a preferential formation of $\mathrm{LTB}_{4}$ compared to 5-HETE with increasing PMA. Nevertheless, the total amount of $\mathrm{LTB}_{4}$ also decreased in a concentration-dependent manner. This could be explained with a higher oxidative stress in neutrophils and reduced cell vitality due to PMA impairing 5-LOX activity towards endogenous AA. Another aspect concerning redox properties of GSH serves attention. The reaction potential of the redox couple GSSG/2 GSH depends not only on the activity ratio between the reduced and oxidized forms as in the case of most other redox couples but also on the concentration of GSH [Schafer and 
Buettner 2001]. Thus, a more reduced GSH level in PMA-stimulated cells might much stronger affect the activity of $\mathrm{GpX}$ as in $\mathrm{H}_{2} \mathrm{O}_{2}$-stimulated cells.

In different previous studies stimulation of neutrophils with PMA in addition to A23187 was related to 5-LOX activity. Direct comparisons between these results are difficult due to variable experimental conditions. Werz et al. showed that in neutrophils, pre-stimulated with PMA, the leukotriene biosynthesis was up-regulated [Werz et al. 2001]. This was explained by a higher release of AA and an increased phosphorylation and translocation of 5-LOX. However, the 5-LOX product formation was not evaluated individually, so no conclusion about the product ratio can be drawn. These observations based mainly on the application of suboptimal concentrations of A23187 $(0.1 \mu \mathrm{M})$. Also an increased release of $\mathrm{LTB}_{4}$ by neutrophils synergistically stimulated with PMA and A23187 (0.4 $\left.\mu \mathrm{M}\right)$ was depicted by Liles et al. [Liles et al. 1987]. During these studies only the amount of $\mathrm{LTB}_{4}$ and its metabolites were quantified. Interestingly, the amount of $\mathrm{LTB}_{4}$ induced by higher concentration of $A 23187$ alone $(1 \mu \mathrm{M})$ was not significantly different from that induced by A23187 $(0.4 \mu \mathrm{M})$ plus PMA.

Contrary to this, the pre-incubation with 16-160 nM PMA in addition to A23187 ( $2 \mu \mathrm{M})$ suppressed the recovery of all 5-LOX products by neutrophils from healthy individuals, whereas neutrophils from patients with chronic granulomatous disease (CGD) were unaffected [Hamasaki et al. 1989]. This decrease was attributed to increased ROS production by PMA that may directly affect endogenous $\mathrm{LTB}_{4}$ and convert it to metabolites distinct from $\omega$-oxidations products. However, no such oxidations products derived from $\mathrm{LTB}_{4}$ or 5-HETE were described. We also applied an optimal A23187 concentration and measured a reduction in $\mathrm{LTB}_{4}$ after incubation with PMA. The treatment with the MPOinhibitor 4-ABAH allows the hypothesis of a partially MPO-induced $\mathrm{LTB}_{4}$ reduction.

In conclusion, the activation of MPO by $\mathrm{H}_{2} \mathrm{O}_{2}$ or PMA is able to affect the product profile of 5-LOX in human neutrophils. The pre-stimulation with $\mathrm{H}_{2} \mathrm{O}_{2}$ resulted in a concentrationdependent increase in the ratio of 5-HETE to the sum of $\mathrm{LTB}_{4}+6$-trans-LTB 4 . Whereby, the diminution of $\mathrm{LTB}_{4}$ in PMA-stimulated cells was partially dependent on MPO activity. This coincides well with effects of $\mathrm{HOCl}, \mathrm{HOBr}$ and the $\mathrm{MPO}-\mathrm{H}_{2} \mathrm{O}_{2}-\mathrm{Cl}^{-}$system on the product profile of recombinant 5-LOX [Zschaler et al. 2015]. Any reaction of $\mathrm{HOCl}$ and $\mathrm{AA}$ metabolites could be excluded. Indeed, as previously shown the incubation of $\mathrm{HOCl}$ with an isomer of 5-HETE resulted in the formation of chlorohydrin products, which could be also assumed for $\mathrm{LTB}_{4}$. However, in the presence of potential reaction partners of $\mathrm{HOCl}$, as the thioether group of methionine or other amino acids the formation of chlorohydrin products was disturbed [Zschaler and Arnhold 2014]. In line with this, Lee et al. demonstrated in a reaction of $\mathrm{LTC}_{4}$ with $\mathrm{HOCl}$, that the thioether group is the primary target of $\mathrm{HOCl}$. Thereby, a S-chlorosulfonium ion decomposed into two diastereoisomers of $\mathrm{LTC}_{4}$ sulfoxide and of 6-trans-LTB $\mathrm{L}_{4}$, but only in the absence of further amino acids scavengers [Lee et al. 1982]. Therefore the 5-LOX enzyme represents a better target site for $\mathrm{HOCl}$ than their products. Thus, $\mathrm{HOCl}$ production could have further microbicidal-independent effects in neutrophils. Another example is the formation of $\mathrm{HOCl}$-derived chloramines that can modulate the activation of NF-KB by oxidation of IKB [Gloire et al. 2006]. Interestingly, the incubation of recombinant 5-LOX with monochloramine revealed an increase in the 5-H(p)ETE to 6-trans$\mathrm{LTB}_{4}$ ratio comparable to $\mathrm{HOCl}$ (unpublished results). Therefore, also further $\mathrm{HOCl}$-derived oxidants in neutrophils, like the hydrophobic monochloramine, could modulate 5-LOX activity. In this study the main focus was directed on adequate MPO activators. To further 
elucidate the simultaneous activation of MPO and 5-LOX more physiological stimulants should be tested for influence on 5-LOX product profile.

\section{Authorship}

JZ and JA initiated the study's concept and wrote the manuscript. JZ performed the experiments and analyzed the data.

\section{Conflict of interest disclosure}

The authors declare no conflict of interest.

\section{Acknowledgments}

The authors gratefully acknowledge the financial support provided by the Sächsische Aufbaubank from a funding of the European Regional Development Fund (ERDF) (SAB Project nr: 100116526) and the German Federal Ministry of Education and Research (BMBF1315883). 


\section{References}

Arnhold J, Flemmig J (2010) Human myeloperoxidase in innate and acquired immunity. Arch Biochem Biophys 500, 92-106.

Beers RF, Sizer I (1952) A spectrophotometric method for measuring the breakdown of hydrogen peroxide by catalase. J Biol Chem 195, 133-40.

Chai YC, Ashraf SS, Rokutan K, Johnston RB, Jr., Thomas JA (1994) S-thiolation of individual human neutrophil proteins including actin by stimulation of the respiratory burst: evidence against a role for glutathione disulfide. Arch Biochem Biophys 310, 273-81.

Chapman AL, Hampton MB, Senthilmohan R, Winterbourn CC, Kettle AJ (2002) Chlorination of bacterial and neutrophil proteins during phagocytosis and killing of Staphylococcus aureus. J Biol Chem 277, 9757-62.

Flemmig J, Remmler J, Zschaler J, Arnhold J (2015) Detection of the halogenating activity of heme peroxidases in leukocytes by aminophenyl fluorescein. Free Radic Res 49, 768-76.

Flemmig J, Zschaler J, Remmler J, Arnhold J (2012) The fluorescein-derived dye aminophenyl fluorescein is a suitable tool to detect hypobromous acid ( $\mathrm{HOBr}$ )-producing activity in eosinophils. $J$ Biol Chem 287, 27913-23.

Fu X, Kassim SY, Parks WC, Heinecke JW (2003) Hypochlorous acid generated by myeloperoxidase modifies adjacent tryptophan and glycine residues in the catalytic domain of matrix metalloproteinase-7 (matrilysin): an oxidative mechanism for restraining proteolytic activity during inflammation. J Biol Chem 278, 28403-9.

Gijon MA, Leslie CC (1999) Regulation of arachidonic acid release and cytosolic phospholipase A2 activation. J Leukoc Biol 65, 330-6.

Gloire G, Legrand-Poels S, Piette J (2006) NF-kappaB activation by reactive oxygen species: fifteen years later. Biochem Pharmacol 72, 1493-505.

Graham FD, Erlemann KR, Gravel S, Rokach J, Powell WS (2009) Oxidative stress-induced changes in pyridine nucleotides and chemoattractant 5-lipoxygenase products in aging neutrophils. Free Radic Biol Med 47, 62-71.

Grisham MB, Jefferson MM, Melton DF, Thomas EL (1984) Chlorination of endogenous amines by isolated neutrophils. Ammonia-dependent bactericidal, cytotoxic, and cytolytic activities of the chloramines. J Biol Chem 259, 10404-13.

Haeggstrom JZ, Funk CD (2011) Lipoxygenase and leukotriene pathways: biochemistry, biology, and roles in disease. Chem Rev 111, 5866-98.

Hamasaki T, Sakano T, Kobayashi M, Sakura N, Ueda K, Usui T (1989) Leukotriene B4 metabolism in neutrophils of patients with chronic granulomatous disease: phorbol myristate acetate decreases endogenous leukotriene B4 via NADPH oxidase-dependent mechanism. Eur J Clin Invest 19, 404-11.

Hatzelmann A, Schatz M, Ullrich V (1989) Involvement of glutathione peroxidase activity in the stimulation of 5-lipoxygenase activity by glutathione-depleting agents in human polymorphonuclear leukocytes. Eur J Biochem 180, 527-33.

Hirche TO, Gaut JP, Heinecke JW, Belaaouaj A (2005) Myeloperoxidase plays critical roles in killing Klebsiella pneumoniae and inactivating neutrophil elastase: effects on host defense. $J$ Immunol 174, 1557-65. 
Klebanoff SJ (1970) Myeloperoxidase: contribution to the microbicidal activity of intact leukocytes. Science 169, 1095-7.

Klebanoff SJ, Kettle AJ, Rosen H, Winterbourn CC, Nauseef WM (2013) Myeloperoxidase: a front-line defender against phagocytosed microorganisms. J Leukoc Biol 93, 185-98.

Kutter D (1998) Prevalence of myeloperoxidase deficiency: population studies using Bayer-Technicon automated hematology. J Mol Med (Berl) 76, 669-75.

Lee CW, Lewis RA, Corey EJ, Barton A, Oh H, Tauber Al, Austen KF (1982) Oxidative inactivation of leukotriene C4 by stimulated human polymorphonuclear leukocytes. Proc Natl Acad Sci U S A 79, 416670.

Liles WC, Meier KE, Henderson WR (1987) Phorbol myristate acetate and the calcium ionophore A23187 synergistically induce release of LTB4 by human neutrophils: involvement of protein kinase C activation in regulation of the 5-lipoxygenase pathway. J Immunol 138, 3396-402.

Maas RL, Ingram CD, Taber DF, Oates JA, Brash AR (1982) Stereospecific removal of the DR hydrogen atom at the 10-carbon of arachidonic acid in the biosynthesis of leukotriene A4 by human leukocytes. $J$ Biol Chem 257, 13515-9.

Nauseef WM (2007) How human neutrophils kill and degrade microbes: an integrated view. Immunol $\operatorname{Rev} 219,88-102$.

Nauseef WM, Volpp BD, McCormick S, Leidal KG, Clark RA (1991) Assembly of the neutrophil respiratory burst oxidase. Protein kinase $C$ promotes cytoskeletal and membrane association of cytosolic oxidase components. J Biol Chem 266, 5911-7.

Newcomer ME, Gilbert NC (2010) Location, location, location: compartmentalization of early events in leukotriene biosynthesis. J Biol Chem 285, 25109-14.

Parry MF, Root RK, Metcalf JA, Delaney KK, Kaplow LS, Richar WJ (1981) Myeloperoxidase deficiency: prevalence and clinical significance. Ann Intern Med 95, 293-301.

Pattison DI, Davies MJ (2001) Absolute rate constants for the reaction of hypochlorous acid with protein side chains and peptide bonds. Chem Res Toxicol 14, 1453-64.

Powell WS, Rokach J (2013) The eosinophil chemoattractant 5-oxo-ETE and the OXE receptor. Prog Lipid Res 52, 651-65.

Radmark O, Werz O, Steinhilber D, Samuelsson B (2015) 5-Lipoxygenase, a key enzyme for leukotriene biosynthesis in health and disease. Biochim Biophys Acta 1851, 331-9.

Roos D, Weening RS, Wyss SR, Aebi HE (1980) Protection of human neutrophils by endogenous catalase: studies with cells from catalase-deficient individuals. J Clin Invest 65, 1515-22.

Rouzer CA, Matsumoto T, Samuelsson B (1986) Single protein from human leukocytes possesses 5lipoxygenase and leukotriene A4 synthase activities. Proc Natl Acad Sci USA 83, 857-61.

Rouzer CA, Samuelsson B (1986) The importance of hydroperoxide activation for the detection and assay of mammalian 5-lipoxygenase. FEBS Lett 204, 293-6.

Schafer FQ, Buettner GR (2001) Redox environment of the cell as viewed through the redox state of the glutathione disulfide/glutathione couple. Free Radic Biol Med 30, 1191-212.

Segal AW (2005) How neutrophils kill microbes. Annu Rev Immunol 23, 197-223.

Prostaglandins, Leukotrienes and Essential Fatty Acids (PLEFA), provided by University Library Leipzig [2017] 
Setsukinai K, Urano Y, Kakinuma K, Majima HJ, Nagano T (2003) Development of novel fluorescence probes that can reliably detect reactive oxygen species and distinguish specific species. J Biol Chem $278,3170-5$.

Shao B, Belaaouaj A, Verlinde CL, Fu X, Heinecke JW (2005) Methionine sulfoxide and proteolytic cleavage contribute to the inactivation of cathepsin $\mathrm{G}$ by hypochlorous acid: an oxidative mechanism for regulation of serine proteinases by myeloperoxidase. J Biol Chem 280, 29311-21.

Vissers MC, Winterbourn CC (1995) Oxidation of intracellular glutathione after exposure of human red blood cells to hypochlorous acid. Biochem J 307, 57-62.

Werz O, Burkert E, Samuelsson B, Radmark O, Steinhilber D (2002) Activation of 5-lipoxygenase by cell stress is calcium independent in human polymorphonuclear leukocytes. Blood 99, 1044-52.

Werz O, Klemm J, Samuelsson B, Radmark O (2001) Phorbol ester up-regulates capacities for nuclear translocation and phosphorylation of 5-lipoxygenase in Mono Mac 6 cells and human polymorphonuclear leukocytes. Blood 97, 2487-95.

Wilkie-Grantham RP, Magon NJ, Harwood DT, Kettle AJ, Vissers MC, Winterbourn CC, Hampton MB (2015) Myeloperoxidase-dependent lipid peroxidation promotes the oxidative modification of cytosolic proteins in phagocytic neutrophils. J Biol Chem 290, 9896-905.

Winterbourn CC, Hampton MB, Livesey JH, Kettle AJ (2006) Modeling the reactions of superoxide and myeloperoxidase in the neutrophil phagosome: implications for microbial killing. J Biol Chem 281, 39860-9.

Witko-Sarsat V, Rieu P, Descamps-Latscha B, Lesavre P, Halbwachs-Mecarelli L (2000) Neutrophils: molecules, functions and pathophysiological aspects. Lab Invest 80, 617-53.

Zschaler J, Arnhold J (2014) The hydroperoxide moiety of aliphatic lipid hydroperoxides is not affected by hypochlorous acid. Chem Phys Lipids 184, 42-51.

Zschaler J, Dorow J, Schope L, Ceglarek U, Arnhold J (2015) Impact of myeloperoxidase-derived oxidants on the product profile of human 5-lipoxygenase. Free Radic Biol Med 85, 148-56. 